\title{
CHARACTERIZATION OF ACTIVE CARBON PREPARED FROM COCONUTS SHELLS USING FTIR, XRD AND SEM TECHNIQUES
}

\author{
Andi Ikhtiar Bakti*1, Paulus Lobo Gareso ${ }^{2}$ \\ ${ }^{1,2}$ Departement of Physics, Faculty of Mathematics and Natural Sciences, Universitas Hasanuddin, \\ Makassar-South Sulawesi, Indonesia \\ *Correspondence address: andiikhtiar@yahoo
}

Accepted: October $25^{\text {th }}, 2017$. Approved: February $2^{\text {th }}, 2018$. Published: April $24^{\text {th }}, 2018$

\begin{abstract}
Activated carbon is produced from coconut shells through physical and chemical activation. With pyrolysis method, the optimum activation temperature for physics activation is $600^{\circ} \mathrm{C}$, and for chemical, activation is to soak it in activator $\mathrm{ZnCl}_{2} 10 \%$ and $\mathrm{Na}_{2} \mathrm{Ca}_{3} 10 \%$. Activated carbon was analyzed by Fourier Transformation Infrared (FTIR) and X-ray Diffraction (XRD) methods. The FTIR result showed that the coconut shells succeeds in becoming carbon. The XRD results confirm the existence of several phases of crystals like graphite around the peaks of $36^{\circ}$ and $44^{\circ}$, there are two wide diffraction peaks and can be interconnected with carbon and graphite content. The SEM result showed that the carbonization of pyrolysis and activation processes created porosity and a large surface area for absorption.
\end{abstract}

C 2018 Physics Education, UIN Raden Intan, Lampung, Indonesia

Keywords: activated carbon, coconut shell, FTIR, SEM, XRD

\section{INTRODUCTION}

Coconut shell as a raw material is often converted into activated carbon (AramiNiya, Daud, Mjalli, Abnisa, \& Shafeeyan, 2012). Based on data obtained, Southeast Asia was a region with a considerable amount of coconut production with four countries as its main producers; India, Indonesia, Philippines, and Sri Lanka contributing $78 \%$ of coconut production in the world (Rao, A.H.L.Swaroop, Rao, \& Bharath, 2015). In regard to the production of the activated carbon, Indonesia is currently one of the main exporter countries of activated carbon (Cocommunity, 2016).

Activated carbon has been known as the most effective and useful adsorbent for removing pollutants from contaminated gas and liquid flow. This is due to the fact that the activated carbon has a large active surface area which can provide a welldeveloped porous structure of absorption capacity and good mechanical properties (Hidayu, 2016). The fundamental for producing activated carbon was carbonrich organic material (A.R Hidayu, 2016).
The development of methods of reusing waste materials as activated carbon was expected to be a solution in waste utilization, such as jatropha seed, corncobs, coconut shell, palm fiber and sawdust, which proves very good to be converted into activated carbon because of its hard texture and strength due to the high lignin and carbon content and low ash levels of these materials (Lehmann \& Joseph, 2009; Promdee et al., 2017; Rao et al., 2015).

The process of producing activated carbon from coconut shell consists of pyrolysis method, turning coconut shell into charcoal, then activation process. The activation process was divided into two, namely physical activation and chemical activation. The process of physical activation is obtained by carbonization with an oxidizing gas or carbon dioxide in high temperatures $\left(400-1000^{\circ} \mathrm{C}\right)$, while chemical activation was immersed it in the chemical solutions of a certain concentration such as $\mathrm{ZnCl} 2, \mathrm{Na} 2 \mathrm{CO} 3$, $\mathrm{KOH}$, and $\mathrm{KCl}$ (Hung, 2012). Activated carbon produces better carbon crystal 
structures and amorphous structures that are stacked irregularly by carbon rings that are useful for producing an adsorbed gap, with 97\% pure carbon (Pradhan, 2011; Rani, Mohammad, Matali, \& Kadir, 2014).

The activation process is carried out by mixing the initial material with the activation reagent and afterward heating it under the inert atmospheric pressure (A.R Hidayu, 2016). This process was usually performed at lower temperatures and times compared to the process of physical activation. The surface area and the resulting porosity are better than the activation. Therefore, this research used the coconut shell as the main ingredient in making activated carbon considering its abundant material in Indonesia and very affordable market value.

\section{METHOD}

\section{Raw Material}

Coconut shell (CS) was selected for the manufacture of activated carbon. The material was cleaned with aquades several times to remove dust and dirt. The coconut shell sample was then dried in the oven at $110^{\circ} \mathrm{C}$ for 24 hours to remove surface moisture and then milled to the desired size. Then an analysis was performed to find out the volatile and carbon content as well as to measure the composition of each element. This method is similar to the previous research method (Hidayu, Muhammad, Matali, \& Sharifah, 2013).

\section{Activated Carbon}

The coconut shell was activated using physical activation by being fed into a pyrolysis reactor which was heated to a temperature of $600^{\circ} \mathrm{C}$ and it was stored for an hour. The activated carbon was immersed in $\mathrm{ZnCl}_{2} 10 \%$ and $\mathrm{Na}_{2} \mathrm{CO}_{3} 10 \%$ then stored for 24 hours at room temperature. After the activation process was complete, activated carbon was then cleaned with aquades and dried using an oven at $100^{\circ} \mathrm{C}$ for thirty minutes. After that, the activated carbon was sieved using ASTM Standard. The Test Sieving has a size of 70-200 Mesh. The sieve model used consists of three sieve arrangements.

\section{RESULT AND DISCUSSION \\ FTIR Analysis}

Table 1. The major wavenumber in regards to the chemical bonding compound value of FTIR spectra of $\mathrm{ZnCl}_{2}$ and $\mathrm{Na}_{2} \mathrm{CO}_{3}$ (Fan, Dai, \& Huang, 2012).

\begin{tabular}{llcc}
\hline Wave number $\left(\mathrm{cm}^{-1}\right)$ & Assignments & $\mathrm{ZnCl}_{2}$ & $\mathrm{Na}_{2} \mathrm{CO}_{3}$ \\
\hline $3500-3300$ & O-H Stretching (intermolecular hydrogen bonded) & & \\
$2930-2900$ & C-H Asym. Stretching & $*$ & $*$ \\
2720 & C-H (aldehydes) & & \\
1740 & C=O stretching in esters & & \\
$1625-1610$ & C=C Aromatic skeletal stretching & $*$ & $*$ \\
$1580-1570$ & C=C stretching band & & \\
$1450-1420$ & C-H Asymmetric. Bending & & \\
$1375-1317$ & C-H Asymmetric. And symmetric. bending & \\
$1284-1240$ & C-O Asymmetric. stretching of aromatic ethers, & & \\
$1260-1000$ & esters, and phenols & $*$ & $*$ \\
& C-O in carboxylic acids, alcohols, phenols and & & \\
$700-400$ & esters or the P=O bond in phosphate esters & $*$ & $*$ \\
\hline
\end{tabular}




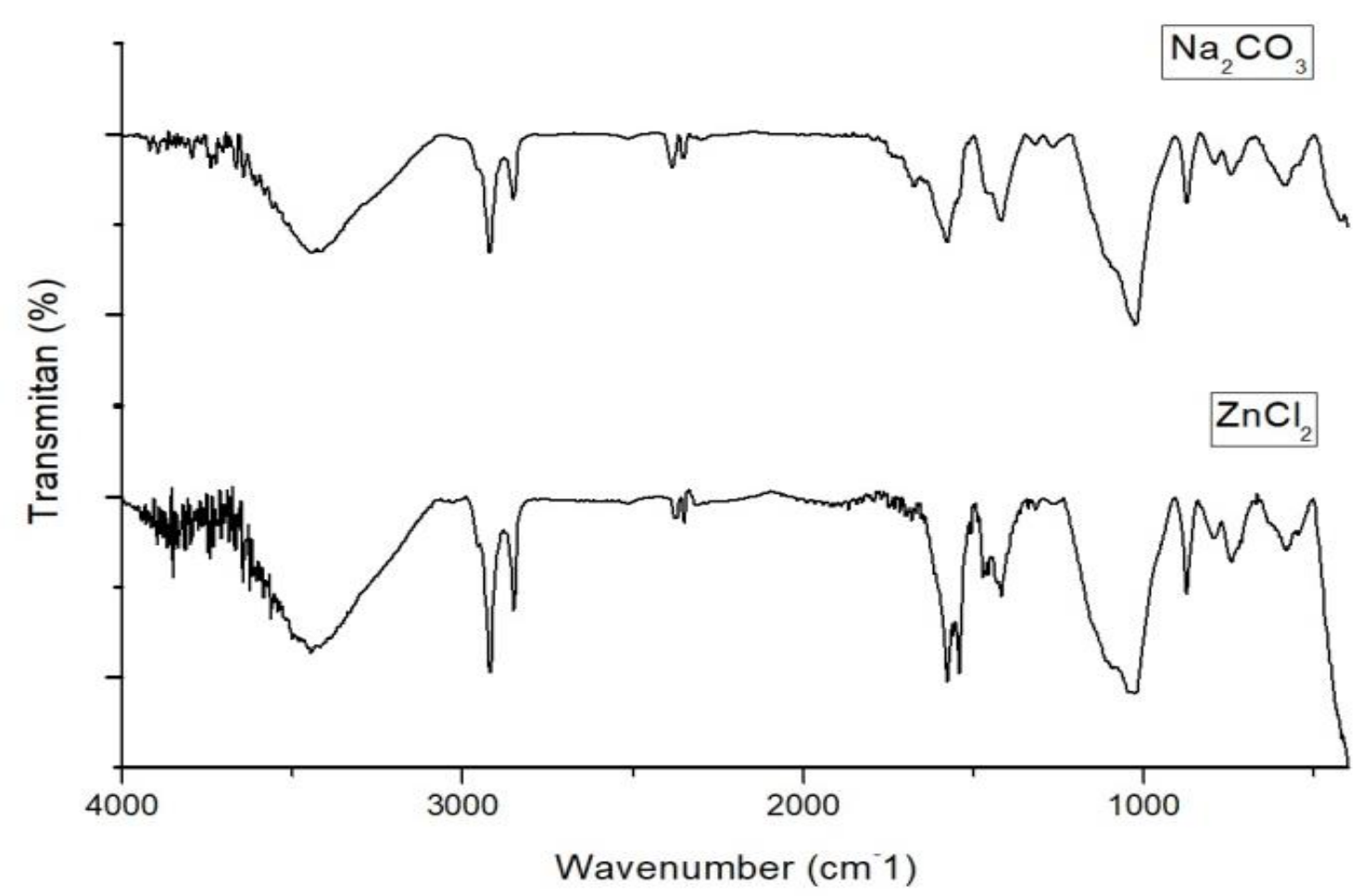

Figure 1. FTIR of activated carbon of $\mathrm{ZnCl}_{2}$ and $\mathrm{Na}_{2} \mathrm{CO}_{3}$

FTIR spectra of the activated carbon of the $\mathrm{ZnCl}_{2}$ AND $\mathrm{Na}_{2} \mathrm{CO}_{3}$ samples, respectively. FTIR spectra contained vast and strong bands at $3200-3500 \mathrm{~cm}^{-1}$ for hydroxyl (O-H) stretching vibration groups. The structure contains many carbons bonds which also act as a remover of hydrogen, and the oxygen atoms of that frequency may contain stretching of amines $\left(\mathrm{NH}_{2}\right)$ and alcohol $(\mathrm{OH})$ groups lost during the activation to $600^{\circ} \mathrm{C}$. This indicates the dehydration of cellulose and lignin components (Shilpi, 2012). Meanwhile, the absorption peak at 2900$2850 \mathrm{~cm}^{-1}$ for the stretching vibration $(\mathrm{CH})$ of the $(-\mathrm{CH}) 3$ group is completely removed from the activated carbon sample. The carbonyl group $(\mathrm{C}=\mathrm{O})$ was observed in samples $\mathrm{ZnCl}_{2}$ and $\mathrm{Na}_{2} \mathrm{CO}_{3}$ in 1740- $1700 \mathrm{~cm}^{-1}$ is expected to come from the lignin network. However, this peak is virtually non-existent after pyrolysis and the immersion activation process with $\mathrm{ZnCl}_{2}$ and $\mathrm{Na}_{2} \mathrm{CO}_{3}$ because it is volatile. Peaks ranging from $1200-1000 \mathrm{~cm}^{-1}$ show the presence of stretching $(\mathrm{C}-\mathrm{O})$ and 830 $\mathrm{cm}^{-1}$ (Si-O) as the result of silica containing minerals (Hidayu, Muhammad, Matali, \& Sharifah, 2013; Rani, Mohammad, Matali, \& Kadir, 2014). The FTIR spectra have confirmed that activated carbon has been successfully converted into carbon (NB, $\mathrm{N}, \& \mathrm{Y}, 2016$ ). For activated carbon, clear during the hardening and activation process, most of the functional group adsorption peak is lost. Because the functional groups of the spectrum feedstock are evaporated as volatile materials when heat is supplied to the sample. This proves that the activation process has been successfully performed and the carbon retains some functional group of sensitive IR, functional group (C-O) (Hesas, Arami-Niya, Daud, \& Sahu, 2013).

\section{Analisis XRD}

Spectrum X-ray diffraction pattern of the activated carbon of $\mathrm{ZnCl}_{2}$ and $\mathrm{Na}_{2} \mathrm{CO}_{3}$ samples. The diffraction peaks are observed at the diffraction angle of $2 \theta=$ 
$29,5^{\circ}, 34,6^{\circ}$ and $39,4^{\circ}$ respectively which corresponds to silicate minerals, iron ore, and quartz. While the rest of the other peaks that are observed at the diffraction angle of $44.5^{\circ}$ corresponding to sodalite, analcime and sodium silicate, respectively (Pradhan, 2011). The two active carbon samples showed two broad diffraction peaks located at $2 \theta=30^{\circ}-40^{\circ}$ and $40^{\circ}-50^{\circ}$ which revealed an amorphous structure that was irregularly stacked by carbon rings and useful for generating an adsorbed gap.

For uncarry Carbon, a sharp peak observed at $44,5^{\circ}$ may be due to the presence of $\mathrm{Zn}$ and $\mathrm{Na}$ used during the carbon activation process (A.R Hidayu, 2016).

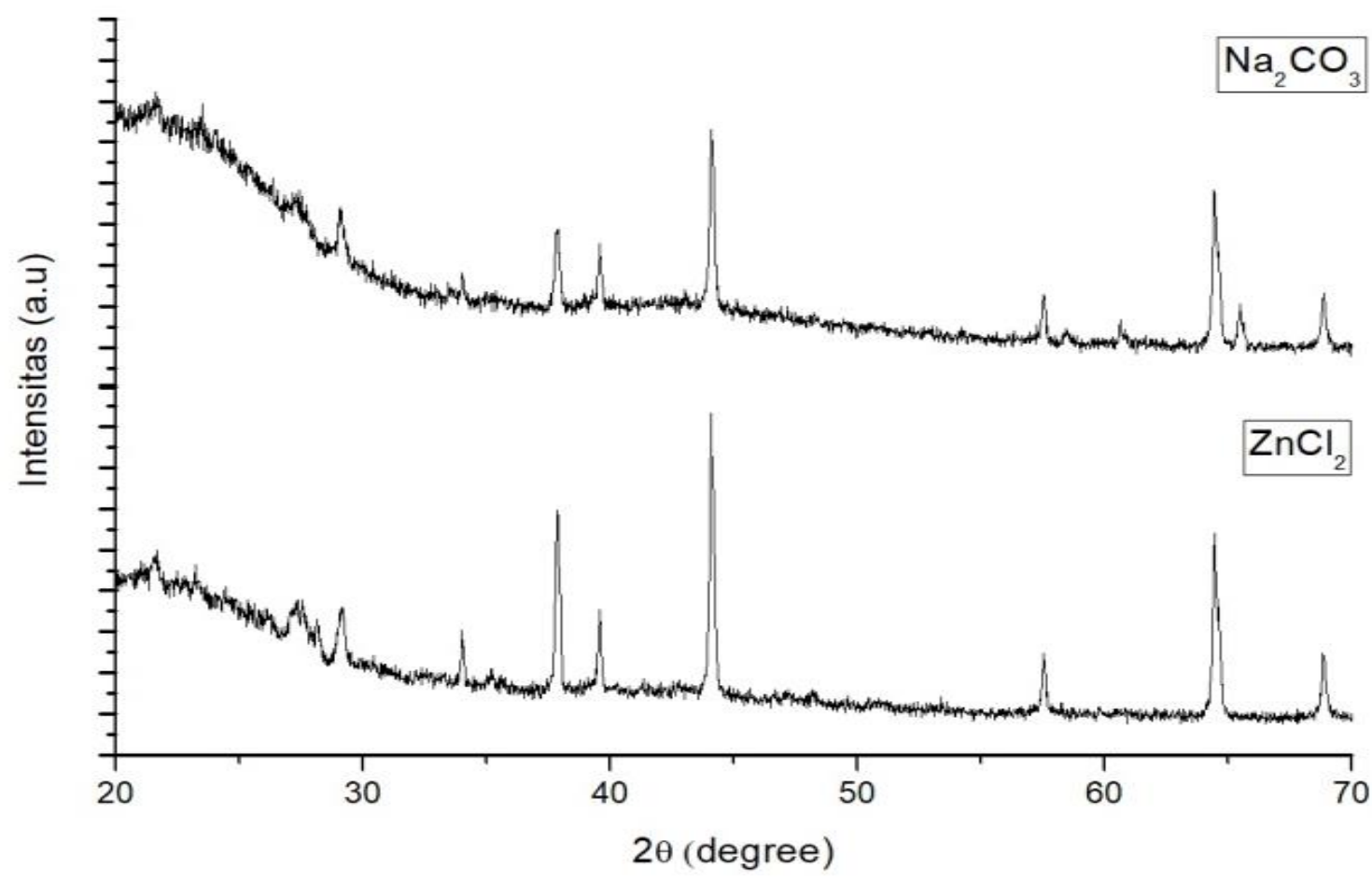

Figure 2. XRD activated carbon of $\mathrm{ZnCl}_{2}$ and $\mathrm{Na}_{2} \mathrm{CO}_{3}$

The findings are in accordance with previous studies by Kushwaha et al., and Rani et al. (Kushwaha, Padmaja, \& Sreelatha, 2012). Samples contain two broad diffraction peaks and can be attributed to the presence of carbon and graphite (Matali, Khairuddin, Sharifah, \& Hidayu, 2013).

\section{SEM Analysis}

Scanning electron microscopy (SEM) was used to observe the surface physical morphology of the samples. Figure 3 shows the SEM images of the microstructure of the raw $\mathrm{ZnCl}_{2}$ and $\mathrm{Na}_{2} \mathrm{CO}_{3}$. Images of the show that the activation stage produced an extensive external surface with quite and pores.

The surface topology differed strongly between raw coconut shell and active carbon physical and chemical (Roozbeh, 2013). Very high porosity was observed on the external surface of the $\mathrm{ZnCl}_{2}$ and $\mathrm{Na}_{2} \mathrm{CO}_{3}$. SEM morphology shows that visible pores were seen in samples of $\mathrm{ZnCl}_{2}$ and $\mathrm{Na}_{2} \mathrm{CO}_{3}$, apparent pores indicating activated carbon processes were successful. 


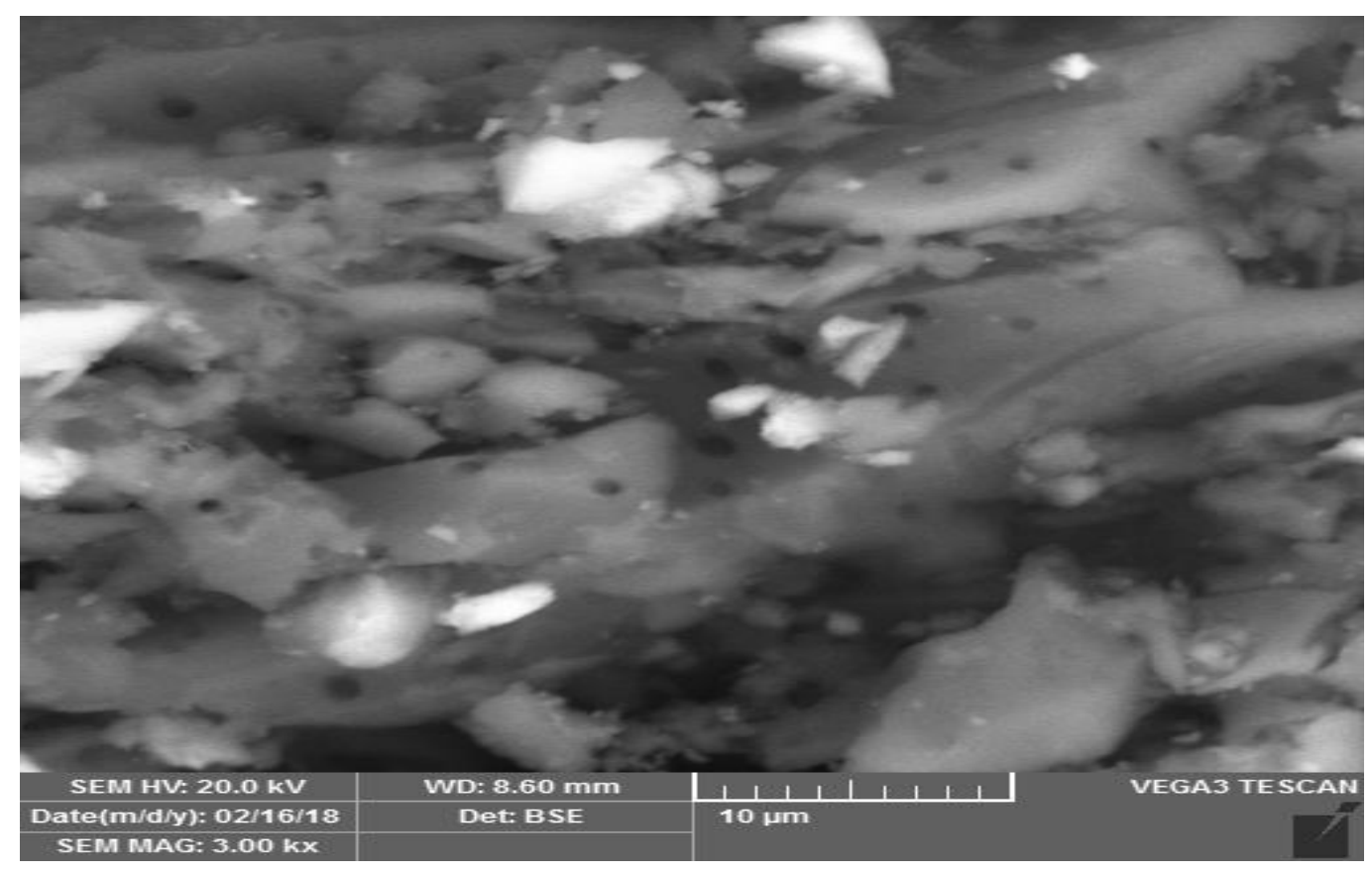

(a)

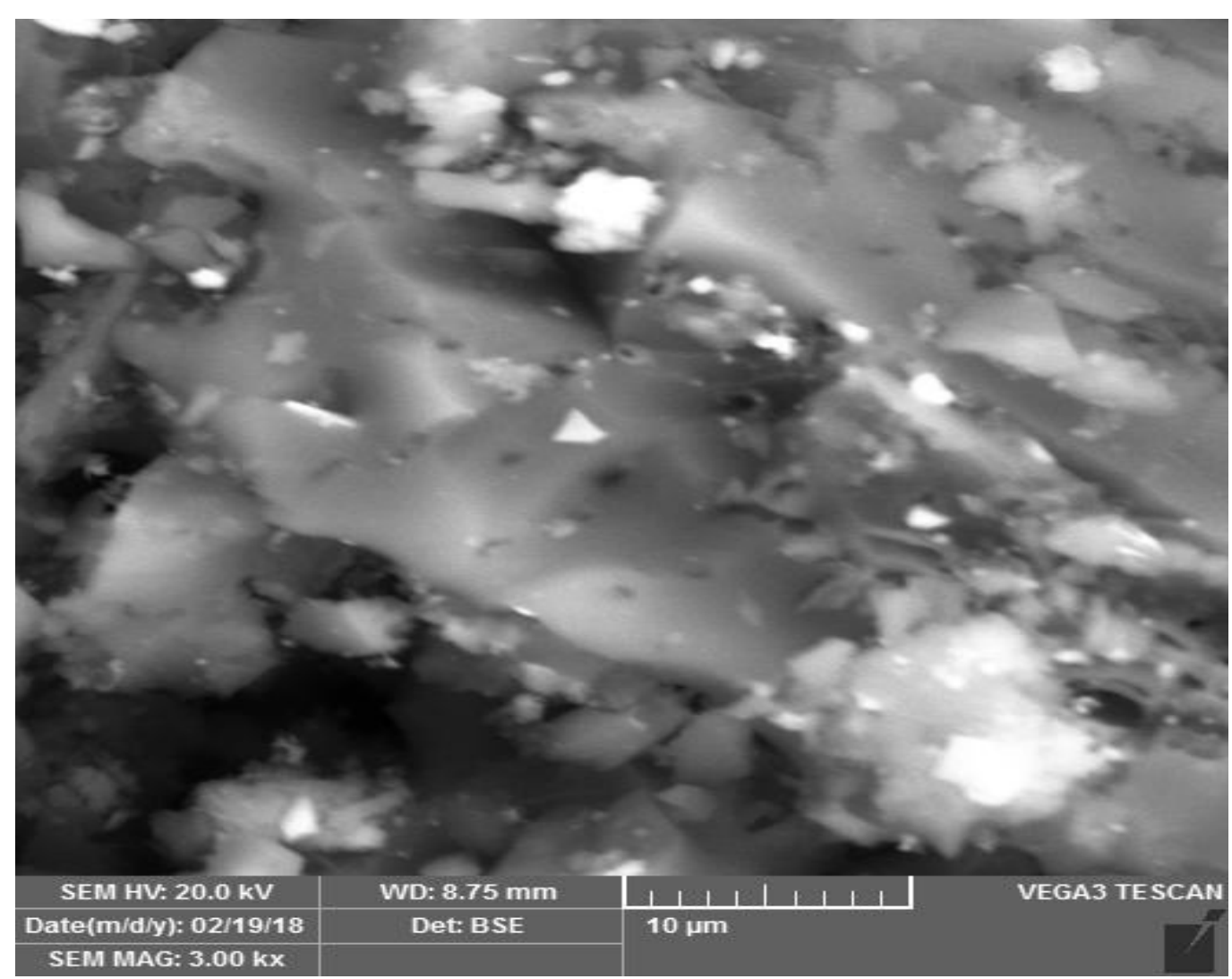

(b)

Figure 3. Morphology on the surface of activated carbon magnification of $3000 x$ (a) $\mathrm{Na}_{2} \mathrm{CO}_{3}$ (b) $\mathrm{ZnCl}_{2}$ 


\section{CONCLUSION}

Activated carbon was produced from coconut shell through physics activation of $600^{\circ} \mathrm{C}$ and chemical activation by immersing it in $10 \% \mathrm{ZnCl}_{2}$ activating agent. Activated carbon was analyzed by Fourier TransformationSpectroscopy Infrared (FTIR)and Xray Diffraction (XRD) methods.

FTIR results show that functional groups of spectrum raw materials were evaporated as volatile materials when the heat was supplied to samples and immersion activation processes with $\mathrm{ZnCl}_{2}$. This proves that the activation process has been successfully performed and the carbon retains some functional IR functional groups, functional groups $(\mathrm{C}$ $\mathrm{O})$ until the coconut shell was successfully converted to carbon. The XRD results confirm the presence of several phases of crystals (graphite) around peaks of $36^{\circ}$ and $44^{\circ}$, with two broad diffraction peaks and can be attributed to the presence of carbon and graphite. For non-transported carbon, a sharp peak observed was at $44.5^{\circ}$. It might be due to the presence of $\mathrm{Zn}$ and $\mathrm{Na}$ used during the carbon activation. In conclusion, coconut shell can be utilized as cheap and efficient raw material for the production of activated carbon with very promising commercial value.The SEMEDS results showed that the carbonization of pyrolysis and activation processes creates porosity and large surface area for absorption, where the pores of the coconut shells and the husk are still visible, in contrast to CA8 and CAZ activated carbon that showed the pores that indicate activated carbon process was successful.

\section{REFERENCES}

A.R Hidayu, N. M. (2016). Preparation and characterization of impregnated activated carbon from palm kernel shell coconut shell for $\mathrm{CO} 2$ capture. Procedia Engineering 148, 106-
113.

Arami-Niya, A., Daud, W. M. A. W., Mjalli, F. S., Abnisa, F., \& Shafeeyan, M. S. (2012). Production of microporous palm shell based activated carbon for methane adsorption: modeling and optimization using response surface methodology. Chemical Engineering Research and Design, 776-784.

Cocommunity, T. (2016). Initiatives Towards Product Diversification Seek Out Viable Opportunities in the Coconut Industry. Monthly Newsletter of the Asian and Pacific Coconut Community, 66(8), 1-32.

Fan, M., Dai, D., \& Huang, B. (2012). Fourier Transform Infrared Spectroscopy for Natural Fibers. Retrieved from www.intechopen.com

Hesas, R. H., Arami-Niya, A., Daud, W. M. A. W., \& Sahu, J. N. (2013). Preparation and Characterization of Activated Carbon from Apple Waste by Microwave-Assisted Phosphoric Acid Activation: Application in Methylene Blue Adsorption. Bio Resources, 8(2), 2950-2966.

Hidayu, A. ., Muhammad, N. F., Matali, S., \& Sharifah, A. S. . (2013). Characterization of activated carbon prepared from oil palm empty fruit bunch using BET and FTIR techniques. Procedia Engineering 68, 379-384.

Hung, J. J. (2012). The Production of Activated carbon from Coconut Shells Using Pyrolysis and Fluidized Bed Reactors. Arizona: The University of Arizona.

Kushwaha, S., Padmaja, P., \& Sreelatha, G. (2012). Physical and Chemical Modified Forms of Palm Shell Preparation, Characterization, and Preliminary Assessment. Retrieved from https://www.research.net/publicatio 
n/257594337, 1-17

Lehmann, J., \& Joseph, S. (2009). Biocha for environmental management. Earthscan.

Matali, S., Khairuddin, S. A., Sharifah, A. S. A. K., \& Hidayu, A. R. (2013). Removal of Selected Gaseous Effluent Using Activated Carbon Derived from Oil Palm Waste: An Overview. IEEE Symposium on Business, Engineering, and Industrial Applications.

NB, O., N, S., \& Y, U. (2016). The activated carbon of Oil Palm Empty Fruit (EFB); Core and Shaggy. Procedia Engineering 148, 758764.

Pradhan, S. (2011). Production and characterization of Activated Carbon produced a suitable Industrial sludge. Odisha, India: Department of Chemical Engineering National Institute of Technology Rourkela.

Promdee, K., Chanvidhwatanakit, J.,
Satitkune, S., Boonmee, C., Kawichai, T., Jarernprasert, S., \& Vitidsant, T. (2017). Characterization of Carbon Materials and Differences from Activated Carbon Particle (ACP) and Coal Briquettes Product (CBP) Derived From Coconut Shell Via Rotary Kiln. Renewable and Sustainable Energy Reviews 75, 1175-1186.

Rani, N. H. A., Mohammad, nor F., Matali, S., \& Kadir, S. A. S. A. (2014). Preparation and characterization of activated carbon made from oil palm empty fruit bunch. Engineering Materials, 594595.

Rao, K. V., A.H.L.Swaroop, Rao, D. P. K. R., \& Bharath, C. N. (2015). Study on Strength Properties of Coconut Shell Concrete. International Journal of Civil Engineering and Technology (IJCIET), 42-61. 